\title{
Simulation of wave action on a moored container carrier inside Sines' Harbour
}

\author{
L. Pinheiro, C.J.E.M. Fortes \& B.M. Abecassis Jalles \\ National Laboratory for Civil Engineering, Portugal
}

J.A. Santos
Instituto Superior de Engenharia de Lisboa, Portugal

L. Fernandes

Instituto Superior Técnico, Portugal

\begin{abstract}
The integrated numerical tool SWAMS (Simulation of Wave Action on Moored Ships) is used to simulate the behavior of a moored container carrier inside Sines' Harbour. Wave, wind, currents, floating ship and moorings interaction is discussed. Several case scenarios are compared differing in the layout of the harbour and wind and wave conditions. The several harbour layouts correspond to proposed alternatives for the future expansion of Sines' terminal XXI that include the extension of the East breakwater and of the quay. Additionally, the influence of wind on the behavior of the ship moored and the introduction of pre tensioning the mooring lines was analyzed. Hydrodynamic forces acting on the ship are determined using a modified version of the WAMIT model. This modified model utilizes the Haskind relations and the non-linear wave field inside the harbour obtained with finite element numerical model, BOUSS-WMH (Boussinesq Wave Model for Harbors) to get the wave forces on the ship. The time series of the moored ship motions and forces on moorings are obtained using BAS solver.
\end{abstract}

\section{INTRODUCTION}

In view of the implementation, by the Port of Sines, the expansion plan of Terminal XXI, several studies, including agitation and long waves studies were carried out by LNEC. In fact harbour resonance is a phenomenon that has already occurred in this basin as well as extreme sea-wave events that cause movements on the moored ships that exceed the limits established for safe loading/unloading operations. Some episodes of broken mooring lines were already recorded. Excessive movements of moored ships induced by sea waves can disrupt loading and unloading of vessels and cause serious problems, including mooring lines failure and the collision of ships with the pier. Hence the importance of a correct characterization of moored ship response to incident sea waves.

For a correct numerical simulation of this behavior it is necessary to couple several distinct numerical models. First, a model for wave propagation inside the harbor, then a model for ship behavior under sea-wave action and finally a model to simulate the combined effect of all the forces acting on the ship including mooring lines, fenders, wind and currents. Several complex phenomena, most of them nonlinear, do affect the evaluation of the ship response to incident waves, due to the limitations and errors of the numerical models involved.

Numerical tools of this type are scarce and with some limitations. Most of them use linear theory to describe the wave-floating structure interaction and a very simplified geometry of the port. However, an accurate representation of the port geometry is important to take into account the evanescent modes close to the ship and to better describe the wave field acting on the ship. Several authors have developed methods to solve this problem using increasingly complex and sophisticated models (Sawaragi \& Kubo, 1982, Sawaragi et al., 1989; Takagi et al., 1993; Sakakibara \& Kubo, 1997, Bingham, 2000, Wenneker et al., 2006 Wenneker \& Molen, 2008).

The SWAMS tool presented in this paper has the innovative feature of coupling a Boussinesq-type model for nonlinear wave propagation with the WAMIT model (Korsemeyer et al., 1988) for ship-wave interaction. Nonlinear effects inside the ports are not negligible in wave propagation (Rusu \& Guedes Soares 2013). Therefore it is important to provide all these effects when evaluating moored ships movements. In addition to these 
phenomena, wave reflection and energy dissipation by bottom friction and wave breaking are also important in harbour areas. The BOUSS-WMH model (Boussinesq Wave Model for Harbours, Pinheiro et al., 2011), incorporates all those phenomena and it allows an accurate description of the evolution of real sea-states (defined by a time series measured on-site measurements or by a specified spectrum) in sheltered areas of variable depth.

Section 2 describes the SWAMS tool, whereas Section 3 shows describes a case study and the numerical implementation. Section 4 presents and discusses the results obtained and Section 5 enumerates the study conclusions.

\section{SWAMS NUMERICAL PACKAGE}

\subsection{Overview}

SWAMS - Simulation of Wave Action on Moored Ships - is an integrated tool for numerical modeling of wave propagation as well as of the behavior of moored vessels within harbors.

It consists of a graphical user interface and a set of modules that deal with the implementation of the numerical models. The user interface allows the introduction and manipulation of data, running the numerical model, as well as viewing the results. Each model corresponds to a module to which are attached the databases that gather all the project information. This tool contributes to the efficiency of this type of numerical studies since it facilitates all the work associated with the construction of data files for each numerical model, the implementation of the numerical model and the visualization of results.

SWAMS is divided into two modules, Figure 1: the WAVEPROP module - for wave propagation and the MOORNAV module - for moored ship behavior.

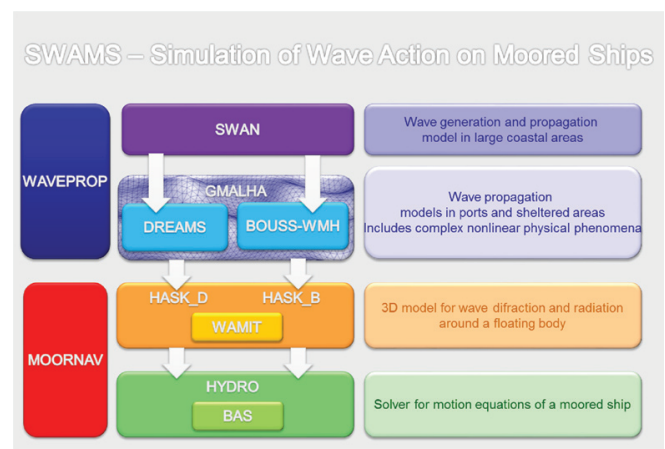

Figure 1. Structure of the numerical package SWAMS.
The graphical representation of the data and results of the SWAMS modules is made with commercial visualization software (Tecplot $360^{\mathrm{TM}}$ and AutoCAD ${ }^{\mathrm{TM}}$ ) or even with MS Excel ${ }^{\mathrm{TM}}$, depending on the corresponding numerical model.

\subsection{The WAVEPROP module for wave propagation}

This module includes three numerical models for wave propagation and a finite element mesh generator:

- SWAN is a non-linear spectral model, Booij et al., (1996), based on the wave action conservation equation that can simulate the propagation of irregular waves;

- DREAMS is a linear finite element model, Fortes (2002), based on the mild slope equation that simulates monochromatic wave propagation;

- BOUSS WMH is a non-linear finite element model, Pinheiro et al., (2011), based on the extended Boussinesq equations deduced by Nwogu, 1993, that are able to simulate the propagation of regular and irregular waves;

- GMALHA is a generator of triangular finite elements, Pinheiro et al., (2008), specifically made for use by the DREAMS and BOUSSWMH models, the density of mesh nodes being variable according to the local wave length.

\subsection{The MOORNAV module for moored ship behavior}

The evaluation of the motion of a ship moored in a berth subject to incident waves is performed using the numerical package MOORNAV (Santos 1994). It is made of two numerical models:

- WAMIT (Korsemeyer et al., 1988) that solves, in the frequency domain, the radiation and diffraction problems of the interaction of a free floating body with sea waves incident on it;

- BAS (Mynett et al., 1985) that assembles and solves, in the time domain, the equations of motion of a ship moored at berth taking into account the time series of forces due to sea waves acting on the ship, the ship impulse-response functions and the constitutive relations of the mooring system elements (mooring lines and fenders).

An interface between the two models was added because the results provided by WAMIT are not exactly the quantities needed for the BAS model operation and because it is necessary to provide to the BAS model the time series of the forces exerted by the sea wave incident on vessel, in addition to the forces due to winds or quasi-stationary currents. 


\section{CASE STUDY}

\subsection{The Terminal XXI of the Port of Sines}

The container terminal of the Port of Sines, also known as Terminal XXI, is located in the southernmost area of the port and is protected from the incident sea waves by the east breakwater.

Until February 2011, the terminal basin was sheltered by a breakwater $1100 \mathrm{~m}$ long. Close to the breakwater head, water depths ranged between 18 and $20 \mathrm{~m}$, whereas in the terminal basin they ranged from 1 to $21 \mathrm{~m}$ approximately. The Container Terminal quay was $380 \mathrm{~m}$ long.

Since February 2011, under the Expansion Plan for the Port of Sines Container Terminal, the east breakwater and the quay were expanded to increase the capacity of the container terminal.

From February to December 2011, the quay was extended to $730 \mathrm{~m}$. In December 2012, the east breakwater extension was concluded then becoming $1500 \mathrm{~m}$ long, as shown in Figure 2.

There are several reports of problems caused by incident waves in the terminal XXI basin, some including excessive motions of ships moored there.

To increase the number of berths at the container terminal, Sines Port Authority proposed a set of alternative configurations for the geometry of the container terminal basin, which consist primarily of changes in length of the east breakwater and in the length of the quay.

Tested solutions for the container terminal geometry consisted of:

- Reference situation (designated as Configuration 0 ) corresponding to a east breakwater length of $1500 \mathrm{~m}$ and a quay length of $940 \mathrm{~m}$;

- Configuration 1: east breakwater extension $250 \mathrm{~m}$ long, making a total length of $1750 \mathrm{~m}$ and quay length of $1250 \mathrm{~m}$;

- Configuration 2: east breakwater extension $300 \mathrm{~m}$ long, making a total length of $1800 \mathrm{~m}$ and a quay length of $1250 \mathrm{~m}$;

- Configuration 3: east breakwater extension $350 \mathrm{~m}$ long, making a total length of $1850 \mathrm{~m}$ and a quay length of $1250 \mathrm{~m}$.

Figure 2 presents the several configurations for the terminal basin, namely the reference situation (or Configuration 0) and Configurations 1, 2 and 3.

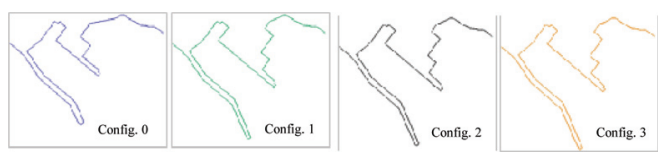

Figure 2. Container terminal layouts. Configurations 0, 1,2 and 3 .

\subsection{Methodology}

The objective of this study is to evaluate which of the proposed configurations (1-3) for the container terminal geometry contributes to greater protection of the terminal basin and in particular to the area near berth one of the quay, see Figure 3. For this a wave condition (south direction and wave period of $10 \mathrm{~s}$ ) was propagated into the terminal basin for the four configurations mentioned before.

The wave propagation calculations were performed with the WMH-BOUSS model for each configuration of the container terminal basin (4, in total), according to the following procedures:

- Digitalization of the study area bathymetry;

- Definition of the computational domain and construction of the finite element mesh;

- Wave propagation calculations.

Then using WAMIT model, one obtains the potentials for the radiation and diffraction problems for a group of periods that contains the period range of the incident sea waves. It is evaluated the impulse response functions and the infinite frequency added masses for the free-floating ship.

Once the time series of the forces exerted by the sea waves incident on the ship are computed, BAS solves, in the time domain, the equations of motion of the ship moored at berth taking into account those forces, the impulse response functions of the ship and the constitutive relations of the mooring system elements.

\subsection{Bathymetry and the computational domain}

The bathymetry of the study area used in the calculations with numerical models was built from information available at LNEC together with information provided by the Port of Sines Authority.

Each of the four configurations of the harbor basin (Configurations 0 and 1-3) are presented in Figure 2. The bathymetry of the computational domain is shown in Figure 3, which includes a detail of the bathymetry inside the port basin.
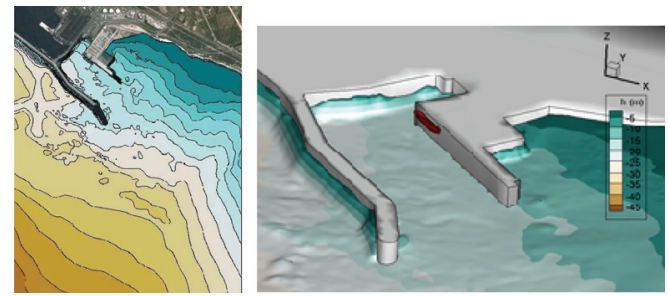

Figure 3. Bathymetry and $3 \mathrm{D}$ view of the basin. 


\subsection{Finite element meshes and boundary conditions}

A finite element mesh is generated based on a criterion of a minimum of eight points per wavelength of a $10 \mathrm{~s}$ period wave. The mesh topology was optimized so that the most equilateral triangles would be possible and the nodal numbering nodal was reordered to optimize the bandwidth required for the numerical model. All this improves the results quality and reduces the computational cost of the numerical simulations. This leads to a mesh with 504925 elements, 253675 points, 343 points on the boundary and a bandwidth of 978 . The minimum area of the elements is $0.645 \mathrm{~m}^{2}$ and the maximum is $167.15 \mathrm{~m}^{2}$. The percentage of points with nonoptimal valence is less than $19.3 \%$.

Boundary conditions that allow for the exit of waves were imposed in sections A1, A2, A3, F, I and $\mathrm{J}$. In the remaining sections, total reflection boundary conditions were established. Figure 4 presents the several stretches of the domain boundary and on the right the viscosities on total absorbing boundaries.

\subsection{Ship and mooring system}

The approach to this problem was to start by solving the frequency domain interaction between the free floating ship and the incident waves. To this end, it was evaluated both the forces along each of the six degrees of freedom of the ship exerted by regular waves incident on the immobilized ship (the so-called diffraction problem) as well as the forces in phase with the acceleration and velocity along each of the six degrees of freedom of the ship-respectively, the added mass and damping coefficients - that are exerted on the ship when it oscillates with sinusoidal movements along each of those degrees of freedom in otherwise calm waters (the so-called radiation problem).

The vessel considered in this study had a length at the waterline of $243 \mathrm{~m}$, a beam of $42 \mathrm{~m}$ and a
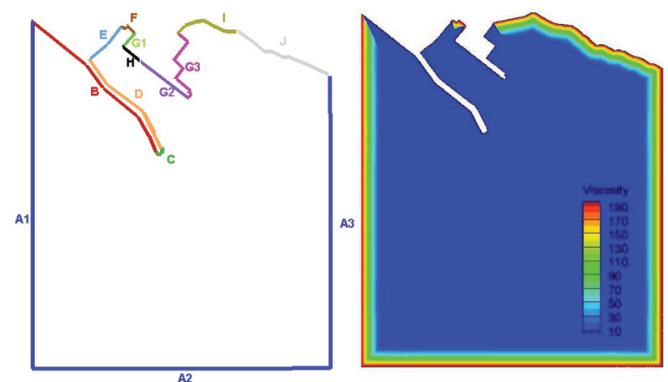

Figure 4. Numerical domain boundaries and respective viscosities. draft of $14.35 \mathrm{~m}$. The hull shape was obtained from an existing panel discretization of the GALP SINES ship made of 853 panels whose coordinates were scaled to achieve the desired size. The resulting discretization panels were divided so that the side of the new panel did not exceed $5 \mathrm{~m}$. It was thus obtained the hull shown in Figure 5, mode of 2694 panels. The volume of water displaced by the hull is $108416 \mathrm{~m}^{3}$.

To simplify the use of WAMIT model, avoiding a panel distribution to shape the bottom of the ship mooring area, it is considered that the vessel was placed on a horizontal area whose water depth is $17 \mathrm{~m}$.

Based on the results of the radiation problem, the forces exerted on the ship over time after an impulsive variation of a velocity component - impulse response functions or retardation functions, Cummins (1962) - and the forces associated with the acceleration of the flow in the vicinity of the ship hull - infinite frequency added masses are evaluated.

Using the matrices formed by these quantities as well as the mass and hydrostatic restoring matrices, together with the forces exerted by the sea state incident on the ship and by the mooring systemwhich implied the definition of the constitutive relations for mooring lines and fenders - it was possible to set-up the motion equation in the time domain. The solution of these equations yielded the time series of motions of the ship's center of gravity and of the efforts in the mooring system.

Figure 6 shows the configuration of the mooring system (2 stern lines, L1 and L2, two bow lines, L7 and L8 and four breast lines, L3, L6, L4 and L5).

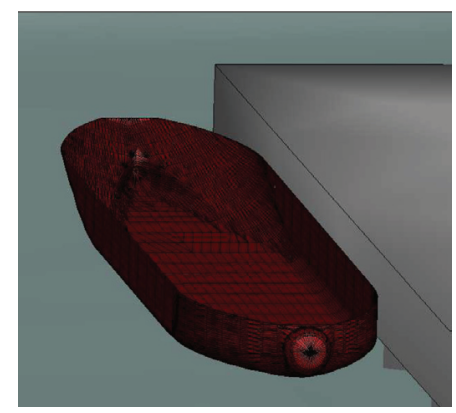

Figure 5. Panels of the ship's submerged hull.

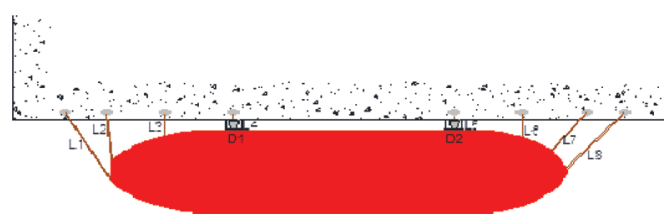

Figure 6. Mooring system layout. 
The contact between the ship and the dock is prevented by two pneumatic fenders (D1 and D2). In all the computations, it was assumed that only stretched mooring lines can exert force on the ship, i.e. no catenary effect was taken into account.

\section{RESULTS AND DISCUSSIONS}

\subsection{Incident sea waves}

During the storms of October 24 and 27, 2011 "ship moving due to sea waves" events were reported by the terminal operators. A regular wave with a wave height of $0.50 \mathrm{~m}$ and $10 \mathrm{~s}$ period from South was simulated.

Figure 7 presents the time series of the freesurface elevation at the entrance boundary of the computational domain and at position corresponding to the center of gravity of the ship.

Figure 8 shows the free-surface elevation in the computational domain $800 \mathrm{~s}$ after the beginning of the simulation. In this figure the diffraction of the wave around the jetty and the reflections that occur within the basin can be seen. Figure 9 shows the agitation coefficient values within the port.

As it can be seen from Figure 9, the position where the ship is to be moored is not very protected from South swells. This is due to the occurrence of reflections between the pier and the inside of the breakwater. When extending the breakwater and the quay this phenomenon is amplified. Going from configuration 1 to configurations 2 and 3

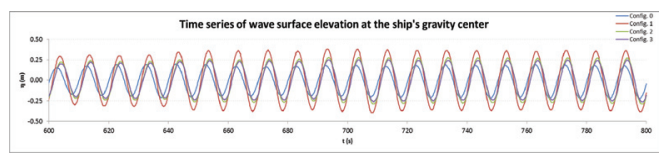

Figure 7. Time series of free-surface elevation.

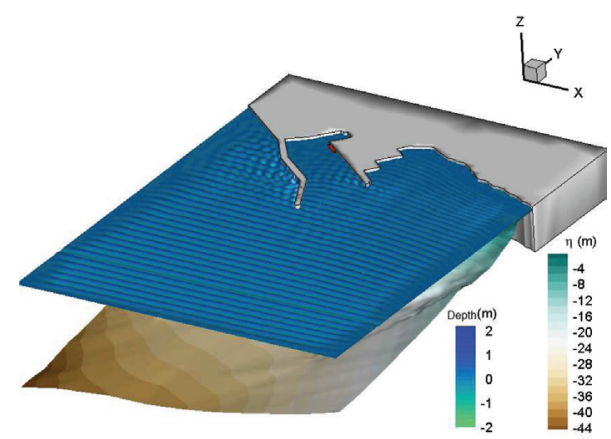

Figure 8. Free surface elevation after $800 \mathrm{~s}$ simulation time (configuration 0 ).

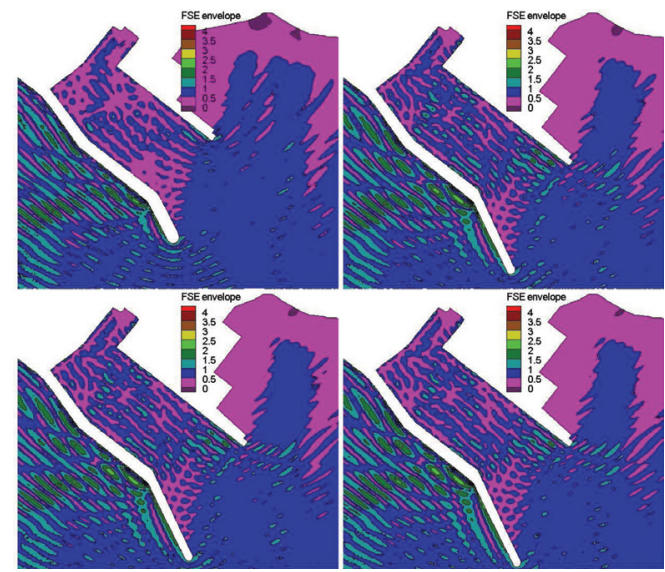

Figure 9. Free surface envelope of wave indexes. Configurations 0 to 3 .
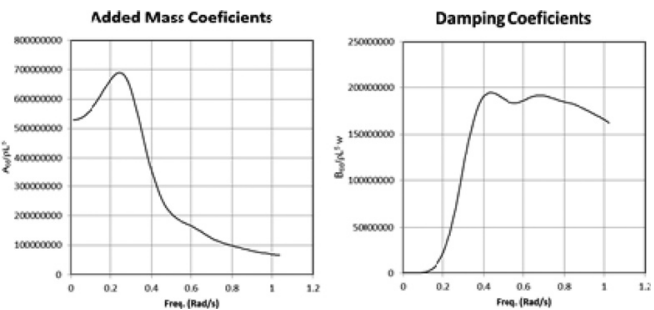

Figure 10. Added mass (right) and damping (left) coefficients for the yaw mode.

(only the breakwater length increases) the agitation coefficient inside the port decreases slightly. It should be noted that within the port the values of this coefficient can reach 2.0 and this happens precisely by the quay at clearly identifiable locations in Figure 9.

\subsection{Moored ship response}

The ship whose behavior is studied had a displacd volume of $108416 \mathrm{~m}^{3}$, a length at waterline of $243 \mathrm{~m}$, a maximum beam of $42 \mathrm{~m}$ and a draft of $14 \mathrm{~m}$. The same constitutive relation was considered for all lines of the mooring system: Linear variation from $0 \mathrm{kN}$ to a maximum load of $1862 \mathrm{kN}$ which corresponds to a length of $4 \%$. The constitutive relation of the fenders is linear also: $8900 \mathrm{kN}$ for a deflection of $1 \mathrm{~m}$.

\subsubsection{Frequency domain}

WAMIT was used to solve the radiation and diffraction problems of the free-floating ship for 87 frequencies between $0.0125 \mathrm{rad} / \mathrm{s}$ and $1.04 \mathrm{rad} / \mathrm{s}$. 


\subsubsection{Time domain}

With the results of the radiation problem in the frequency domain we determined the impulse response functions and the infinite frequency added mass coefficients needed to mount the equations of motion of the moored ship. All the impulse response functions were calculated with a time interval of $0.1 \mathrm{~s}$ for a maximum duration of 50 s. Figure 11 shows the impulse response function for two possible coupling pairs.

Starting with the impulse response functions for the 36 possible pairs (force along $\mathrm{k}$ coordinate due to impulsive speed along coordinate $\mathrm{j}$ ) and the corresponding added mass coefficient for the various frequencies for which the radiation problem was solved, several estimates of the infinite frequency added mass were made. Figure 12 and Figure 13 present the time series of the moored ship motions.

Surge time series, in Figure 12, illustrates the non-linear nature of the response of the dynamic system made of the ship and the mooring system. In fact, for free-surface elevations whose period is about $10 \mathrm{~s}$ the observed moored ship oscillations have a much longer period.

The period of these oscillations is controlled by the existence of mooring lines and fenders, as can be confirmed in Figure 14, Figure 15 and Figure 16,
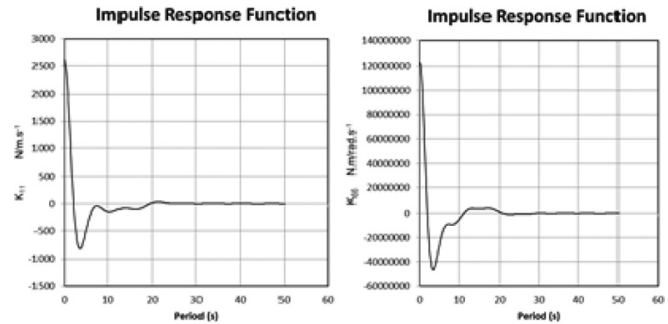

Figure 11. Force due to an impulsive motion of the ship in otherwise calm water.

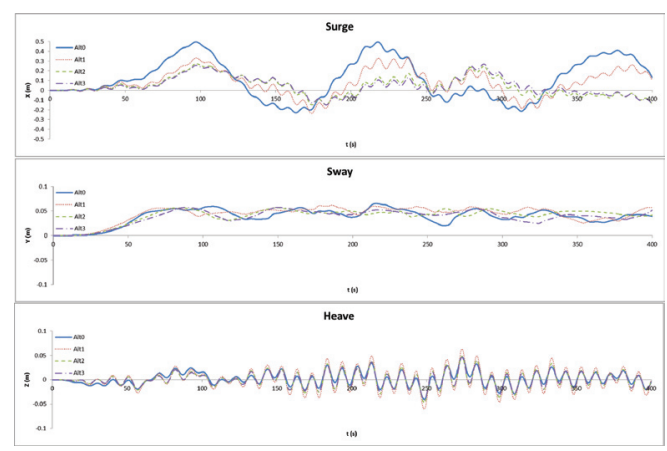

Figure 12. Time series of the moored ship motions: surge, sway and heave.

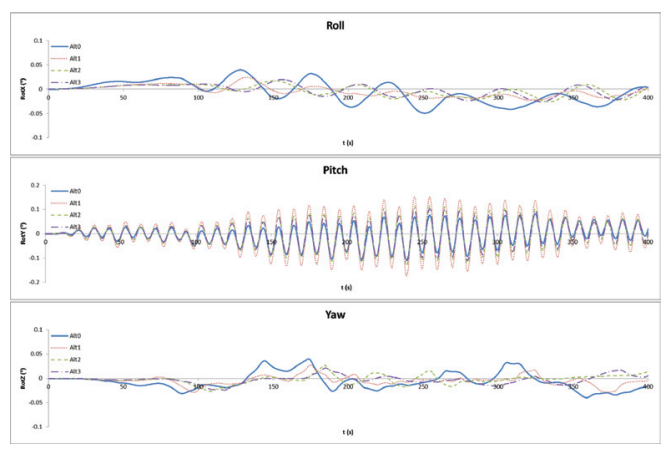

Figure 13. Time series of the moored ship motions: roll, pitch and yaw.

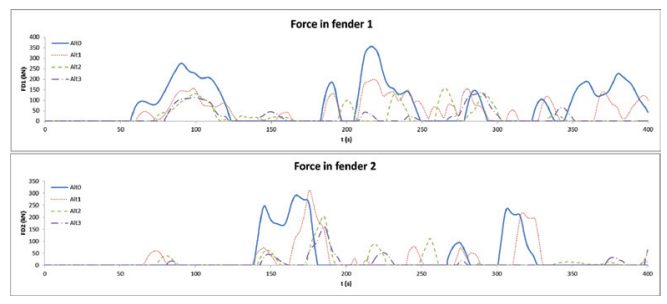

Figure 14. Time series of forces in defenses.

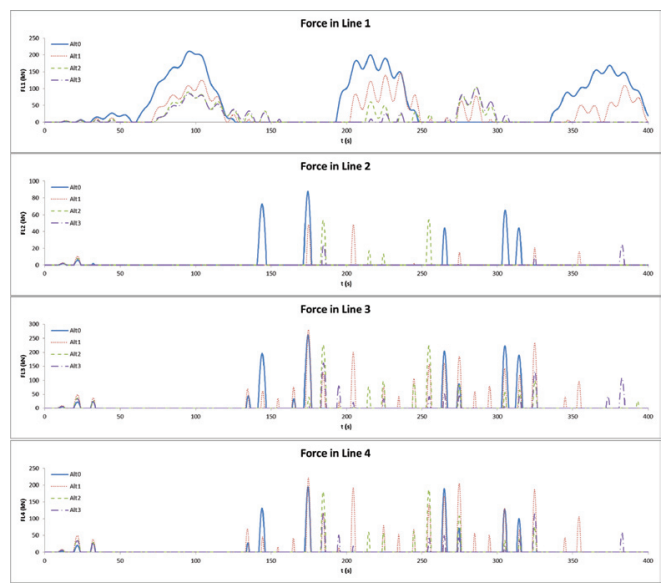

Figure 15. Time series of forces in mooring lines: L1, L2, L3, L4.

with time series, respectively, of the efforts on the fenders and mooring lines.

Since the elements of the mooring system produce forces acting on the ship mainly in the horizontal plane, it is for the motions in this plan that the non-linear behavior is more evident. Configuration 0 is the one which produces the 


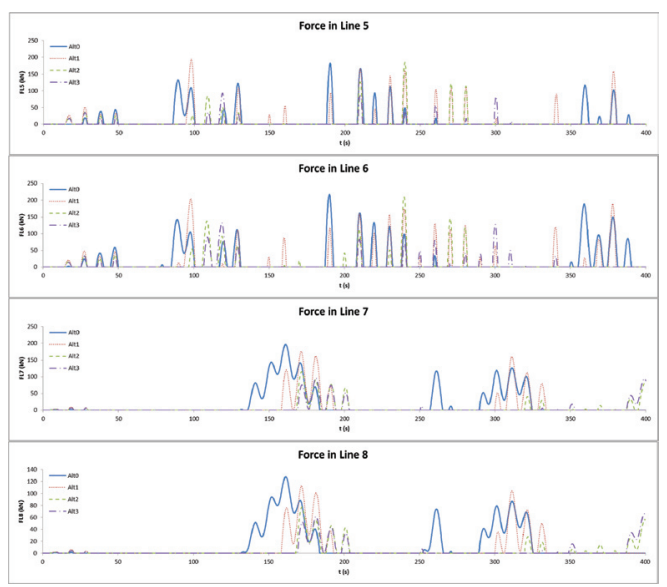

Figure 16. Time series of forces in mooring lines: L5, L6, L7, L8.

highest amplitude of the surge oscillation, followed by configuration 1, 2 and 3 successively.

Figure 12 shows that the sway motion time series is similar in the four configurations. The heave motion has a similar behavior to the incident waves: it has the same period and its amplitude is proportional to the amplitude of the incident waves.

Figure 13 shows that roll, pitch and yaw movements have very small amplitude but different frequencies can be identified in the respective time series. In the case the roll movement the response is influenced by the existence of a vertical wall along the ship side.

Regarding fender efforts, Figure 14, Configurations 0 and 1 are the ones where the highest peaks are attained $(\sim 300 \mathrm{kN})$. In Configurations 2 and 3 such peaks do not go over $150 \mathrm{kN}$.

The most stressed mooring lines are the L1, L3, L4, L5, L6 and L7 (Fig. 15 and Fig. 16). The L2 and $\mathrm{L} 8$ are the least stressed mooring lines. The time series of these efforts do allow the identification of the mooring lines that reduce surge (L1, L7 and L8) since the total duration of periods with efforts in the largest. In these mooring lines it is for Configuration 0 that the efforts reach the highest values whereas the lowest values are obtained with configurations 2 and 3. Remaining mooring lines are stressed in similar periods to the incident wave. In these moorings it is for Configuration 3 that the highest efforts can be observed.

Some cases in which wind and an initial pretension is introduced in the mooring lines are investigated, Figure 17 to Figure 21. The wind has a speed of $15 \mathrm{~m} / \mathrm{s}$ and makes an angle of $30^{\circ}$ with the longitudinal axis of the vessel. The pre-tension in all mooring lines is $10 \%$ of the maximum load, i.e. $186.2 \mathrm{kN}$.

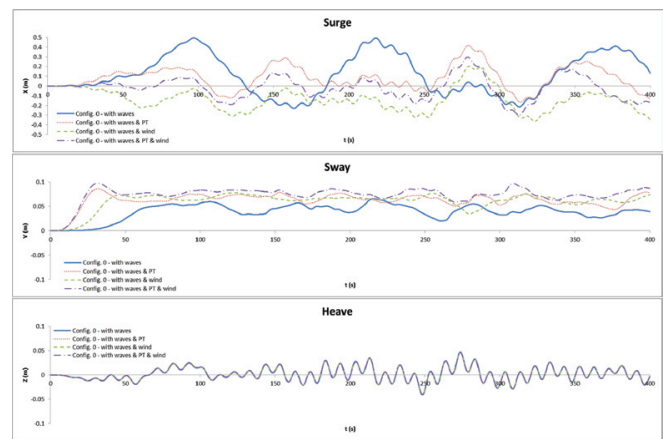

Figure 17. Time series of moored ship motions: surge, sway and heave. Wind of $15 \mathrm{~m} / \mathrm{s}$ and pre-tensioning of the mooring lines of $10 \%$ of the maximum load.

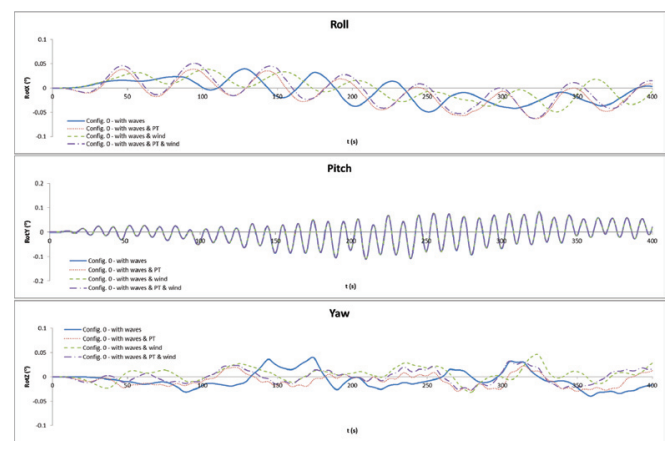

Figure 18. Time series of moored ship motions: roll, pitch and yaw. Wind of $15 \mathrm{~m} / \mathrm{s}$ and pre-tensioning of the mooring lines of $10 \%$ of the maximum load.

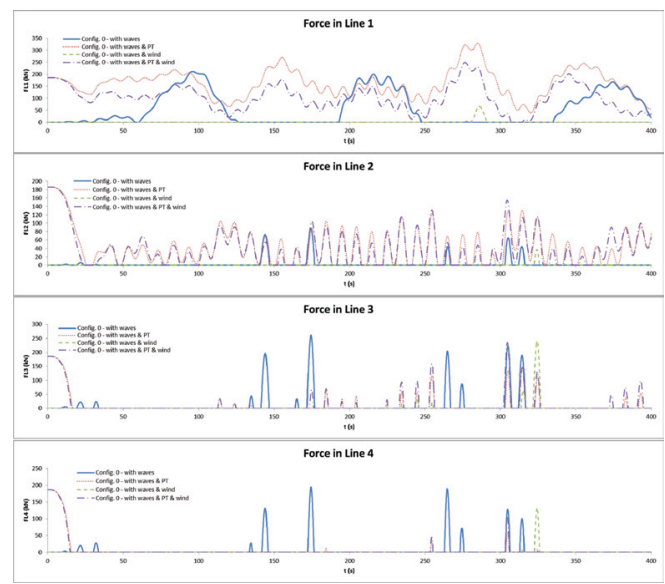

Figure 19. Time series of forces in mooring lines: L1, L2, L3 and L4. Wind of $15 \mathrm{~m} / \mathrm{s}$ and pre-tensioning of the mooring lines of $10 \%$ of the maximum load. 


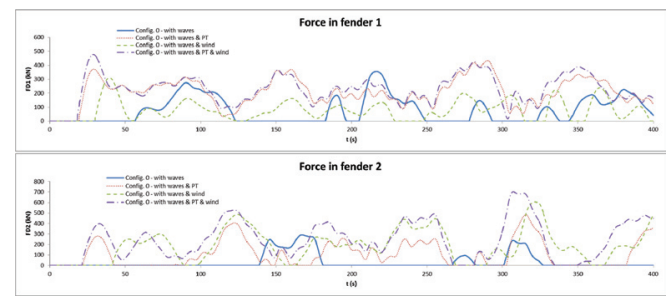

Figure 20. Time series of forces in fenders. Wind $15 \mathrm{~m} / \mathrm{s}$ and pre-tensioning of the mooring lines $10 \%$ of the maximum load.

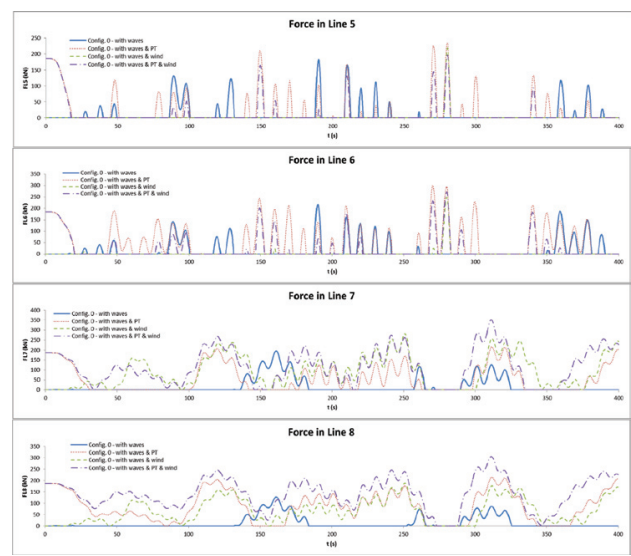

Figure 21. Time series of forces in mooring lines: L5, L6, L7 and L8. Wind of $15 \mathrm{~m} / \mathrm{s}$ and pre-tensioning of the mooring lines $10 \%$ of the maximum load.

Looking at the results, Figure 17 and Figure 18, it becomes evident that the wind influences surge, pushing the ship back, as well as sway, pushing the ship to the quay. This also translates into higher forces on the fenders. The heave motion is not influenced by the presence of wind. The pre-tension in the mooring lines decreases surge but increases sway towards the quay. The rotational movements, roll, pitch and yaw, are not affected by wind or by the pre-tension in the mooring lines.

Since wind comes from the South it pushes the ship towards the quay and this reduces the mooring line forces. Conversely pre-tensioning the mooring lines increases the forces in the moorings, Figure 19 to Figure 21.

\section{CONCLUSIONS}

The paper described the integrated numerical tool, SWAMS, which is able to characterize the response of a ship moored inside a port and subject to incident waves. Using this tool, a sea state was propagated from offshore into the port of Sines and the response of a ship moored at terminal XXI was investigated. 4 different port configurations were tested. A base configuration and 3 alternatives for the extension of the east breakwater that differ only in the length of the breakwater extension, $250 \mathrm{~m}$, $300 \mathrm{~m}$ and $350 \mathrm{~m}$. These alternatives also differ from the base configuration on the quay length and configuration. In addition to incident seawaves, all the configurations were tested with and without wind and with and without pre-tension in the mooring lines.

Configuration 0 is the one with the widest amplitude of surge motion, followed by configurations 1,2 and 3. For the mooring lines Configuration 0 is the one where the highest efforts are observed whereas in Configurations 2 and 3 are the ones with the lowest efforts. As to the fender forces it is configuration 0 and 1 that produce the highest values.

Increasing the breakwater and the quay length (going from configuration 0 to 1 ) increases the wave height inside the port due to higher reflections, but it does not translate into less favorable moored ship behavior. Extending the quay (going from configuration 1 to 2 and to 3 ) reduces wave height, the moored ship motions and the forces in the mooring system.

Wind from South pushes the ship against the quay. This translates into large forces in the fenders and small forces in the mooring lines. Heave is not influenced by the presence of wind. Pre-tensioning the mooring lines decreases surge but increases sway towards the quay, i.e., "pulling ship" to the quay. However the forces in the mooring lines are higher thus increasing the risk of rupture. The rotational movements, roll, pitch and yaw, are not affected by wind or by pre-tensioning.

The results of this example do illustrate the potential of this tool and the type of analysis that can be made. They show to be consistent with what would be expected having the benefit of being able to quantify all quantities involved.

In the future we intend to validate this tool with data from laboratory and/or real-life experiences.

\section{ACKNOWLEDGEMENTS}

The authors thank the information made available by the Sines Port Authority. They thank also the Portuguese Foundation for Science and Technology by the doctoral fellowship SFRH/BD/82637/2011 and the HIDRALERTA project. 


\section{REFERENCES}

Bingham H.B. 2000. A hybrid Boussinesq-panel method for predicting the motion of a moored ship, Coastal Engineering, vol 40 (1), pp 21-38.

Booij, N.R., Holthuijsen, L.H., Ris, R.C. 1996. The SWAN wave model for shallow water, ICCE'96, Orlando, pp. 668-676.

Cummins W.E. 1962. Impulse response function and ship motions. Schiffstechnik, 9, 101-109.

Fortes, C.J.E.M. 2002. Nonlinear wave transformations in harbours. A finite element method analysis. PhD. Thesis. Lisbon (in Portuguese).

Korsemeyer F.T., LeeC.-H., Newman J.N., SclavounosP.D. 1988. The analysis of wave effects on tension-leg platforms. 7th Int. Conf. Offshore Mech. and Arctic Engng, Houston, Texas, pp. 1-14.

Molen, W., Wenneker, I. 2008. Time-domain calculation of moored ship motions in nonlinear waves, Coastal Engineering, Vol. 55 (5) May, pp 409-422.

Mynett, A.E., Keunig, P.J., Vis, F.C. 1985. The dynamic behaviour of moored vessels inside a harbour configuration. Int. Conf. on Num. Mod. Ports and Harbours, Birmingham, England: 23-25 April 1985. Cranfield: BHRA, The Fluid Engng Centre.

Nwogu, O. 1993. Alternative form of Boussinesq equations for near-shore wave propagation. J. Waterway, Port, Coast. Ocean Engng, 119(6):618-638.

Pinheiro L., Fortes C.J.E.M., Santos J.A., Fernandes L., Walkley M. 2011. Boussinesq-type Numerical Model for Wave Propagation Near Shore and Wave Penetration in Harbors. MARTECH 2011. Lisbon 10-12 May.
Pinheiro, L.V., Fortes, C.J., Fernandes J.L. 2008. Gerador de Malhas de Elementos Finitos para a Simulação Numérica de Propagação de Ondas Marítimas. Métodos Numéricos para Cálculo y Diseño en Ingeniería (RIMNI). Vol.4, 4 December.

Rusu, E and Guedes Soares, 2013: Modeling waves in open coastal areas and harbors with phase resolving and phase averaged models, Journal of Coastal Research, 29 (6) 1309-1325.

Santos, J.A. 1994. MOORNAV-Numerical model for the behaviour of moored ships. Final report. Lisbon: Report 3/94-B, NATO PO-Waves.

Sawaragi, T., Aoki, S., Hamamoto, S. 1989. Analyses of hydrodynamic forces due to valves acting on a ship in a harbour of arbitrary geometry. 8th Int. Conf. Off. Mech. Arctic Eng., Vol. 2, 117-123.

Sawaragi, T., Kubo, M. 1982. The motions of a moored ship in a harbour basin. Proc. 18th Conf. Coastal Engineering ASCE. pp. 2743-2762.

Takagi, K., Naito, S., Hirota, K. 1993. Hydrodynamic forces acting on a floating body in a harbour of arbitrary geometry. 3rd Int. Offshore and Polar Eng. Conf. III, 192-199.

Wenneker, I., Borsboom, M.J.A., Pinkster, J.A., Weiler, O.M. 2006. A Boussinesq-type wave model coupled to a diffraction model to simulate wave-induced ship motion. 31st PIANC Congress. Estoril, Portugal. May. 